\title{
Endogenous cardiac stem cells for the treatment of heart failure
}

This article was published in the following Dove Press journal:

Stem Cells and Cloning:Advances and Applications

22 March 2013

Number of times this article has been viewed

\author{
Tania Fuentes \\ Mary Kearns-Jonker \\ Department of Pathology and \\ Human Anatomy, Loma Linda \\ University School of Medicine, \\ Loma Linda, CA, USA
}

\begin{abstract}
Stem cell-based therapies hold promise for regenerating the myocardium after injury. Recent data obtained from phase I clinical trials using endogenous cardiovascular progenitors isolated directly from the heart suggest that cell-based treatment for heart patients using stem cells that reside in the heart provides significant functional benefit and an improvement in patient outcome. Methods to achieve improved engraftment and regeneration may extend this therapeutic benefit. Endogenous cardiovascular progenitors have been tested extensively in small animals to identify cells that improve cardiac function after myocardial infarction. However, the relative lack of large animal models impedes translation into clinical practice. This review will exclusively focus on the latest research pertaining to humans and large animals, including both endogenous and induced sources of cardiovascular progenitors.
\end{abstract}

Keywords: Isl1, iPSC, large animal, c-kit, cardiosphere

\section{Introduction}

The ability to harness the regenerative capacity of stem cells for use in cardiovascular repair could revolutionize the treatment of patients with heart failure. Recently, phase I clinical trials using endogenous stem cell populations isolated directly from the heart have shown a significant improvement in cardiac function and patient outcome over a 1 - to 2-year trial period. Although further optimization will be necessary to achieve functional improvement that exceeds the limits of drug-based therapy, stem cells could conceivably become a common treatment modality for patients with compromised heart function in the future. At present, endogenous cardiovascular progenitors are being isolated in the form of cardiospheres, cardiosphere-derived cells (CDCs), enriched c-kit (tyrosine-protein kinase)-positive progenitors, or as Islet-1 (Isl1)-expressing cardiovascular stem cells that can be expanded in vitro and are resident in the heart itself. Preclinical work using comparable cells in large animal models is limited; however, it is these models that have provided new insight into current limitations in safety and long-term efficacy that must be addressed if the optimal progenitors and conditions for cell-based therapy are to be defined. The latest research in this area will be summarized in this review, which is focused on both endogenous cardiovascular progenitors and induced pluripotent stem cells, which can now be readily differentiated into cardiovascular progenitors with increased efficacy and safety from autologous sources for the treatment of heart failure.

\section{Induced pluripotent stem cells}

Recently, induced pluripotent stem cells (iPSCs) have been given increasing attention with respect to regenerating the myocardium after injury. iPSCs are derived from submit your manuscript | www.dovepress.com

Dovepress

http://dx.doi.org//0.2147/SCCAA.S29221
Stem Cells and Cloning:Advances and Applications 2013:6 I-12 article which permits unrestricted noncommercial use, provided the original work is properly cited. 
differentiated adult cells that have been induced to a state of pluripotency through a process of genetic reprogramming. This procedure for producing stem cells mitigates the ethical concerns associated with the isolation and use of embryonic stem cells. iPSCs capable of differentiation into the cardiac lineage have been created from a variety of tissues, including fibroblasts, ${ }^{1}$ keratinocytes, ${ }^{2}$ human cord blood, ${ }^{3,4}$ human foreskin fibroblasts, ${ }^{5}$ and peripheral blood T lymphocytes. ${ }^{6}$ The process of reprogramming is accomplished by inducing the overexpression of genes, such as octamer-binding protein 3/4 (OCT3/4), SRY-box 2 (SOX2), Kruppel-like factor 4 (KLF4), and myc proto-oncogene protein (c-MYC). The inclusion of c-MYC in reprogramming causes cells to have a higher tendency towards cancer formation, as c-MYC is a potent proto-oncogene. Alternative methods to induce pluripotency have now been developed to promote reprogramming via SOX2 and OCT4, or by overexpression of NANOG, LIN28, OCT4, and SOX2. ${ }^{3,4}$ Interestingly, generation of iPSC without c-MYC has been shown to favor generation of iPSCs with a greater tendency towards cardiac differentiation. ${ }^{7}$

\section{iPSCs for cardiac regeneration therapy}

The process of creating cardiomyocytes through iPSC differentiation produces cardiomyocytes that are phenotypically and proteomically similar to embryonic stem cell-derived cardiomyocytes. ${ }^{8-10}$ Cyclosporin A, a widely used immunosuppressant, has been shown to increase differentiation efficiency of iPSCs into cardiomyocytes. ${ }^{11}$ Several groups have halted cardiomyocyte differentiation to create multipotent cardiac progenitors (Table 1$).{ }^{12}$ Isl1 ${ }^{+}$ cardiac progenitors generated using this process are capable of differentiation into all three cardiac lineages. ${ }^{13}$ The transplantation of iPSCs that have been partially differentiated into committed cardiac progenitors has been investigated as a therapy for myocardial infarction (MI). When transplanting partially differentiated human iPSCs (day 6 of a 14-day protocol) into the rat myocardium, Carpenter et al reported a nonsignificant trend towards improvement in left ventricular ejection fraction (LVEF) and demonstrated that a percentage of transplanted cells were retained long-term (10 weeks), with evidence of differentiation into cells of cardiac lineage. ${ }^{14}$

\section{Human iPSCs in large-animal models}

Transplantation of iPSCs after fully differentiating into cells of the cardiac lineage has also been investigated as a therapy (Table 1). Cardiomyocyte sheets derived from differentiated iPSC and used in a pig model of MI significantly increased LVEF (50.7\%) when compared to controls (40.5\%) at 8 weeks after transplantation. Long-term survival of these cells was very limited, however. ${ }^{15}$ To increase long-term cell survival, Kawamura et al cotransplanted an omentum flap (a highly vascularized tissue from the stomach) and was able to demonstrate

Table I Cardiovascular differentiation of human induced pluripotent stem cells

\begin{tabular}{|c|c|c|c|}
\hline & Differentiation protocol & Level of differentiation & Differentiation markers \\
\hline \multicolumn{4}{|l|}{ Tissues fully differentiated } \\
\hline Human cord blood ${ }^{3}$ & $\begin{array}{l}\text { Let embryoid bodies spontaneously } \\
\text { differentiate }\end{array}$ & Fully differentiated & $\begin{array}{l}\text { Nkx2.5, FOG2, } \alpha M H C, \\
\text { TBX5, TBX20, sarcomeric } \\
\alpha \text {-actin, cTNT }\end{array}$ \\
\hline T lymphocytes $^{6}$ & Cell aggregate method & Fully differentiated & $\mathrm{cTnT}$ \\
\hline Fibroblasts' & Activin A and BMP4 & Fully differentiated & $\begin{array}{l}\text { cTnT, MEF2C, MYL2A, } \\
\text { MYHCB, Nkx2.5 }\end{array}$ \\
\hline Keratinocytes $^{2}$ & $\begin{array}{l}\text { Let embryoid bodies spontaneously } \\
\text { differentiate }\end{array}$ & Fully differentiated & $\begin{array}{l}\text { cTnT, sarcomeric } \\
\alpha \text { actin, } \mathrm{MHC}\end{array}$ \\
\hline \multicolumn{4}{|l|}{ Partially differentiated } \\
\hline $\begin{array}{l}\text { Multipotent cardiovascular } \\
\text { progenitor }^{14}\end{array}$ & $\begin{array}{l}4 \text { hours' high-dose activin A, } \\
92 \text { hours' low-dose activin A, } \\
\text { BMP4, FGF }\end{array}$ & Day 6 in protocol & $\begin{array}{l}\text { ckit-, KDR }{ }^{\text {low }}, \text { PDGFR } \alpha \text {, } \\
\text { cTnl, cTnC, } \alpha \text {-actinin, } \\
\alpha S M A, C D 34, \text { CD3। }\end{array}$ \\
\hline$\left.|s|\right|^{+}$progenitors $^{13}$ & $\begin{array}{l}\text { MEF feeders, BMP2, and } \\
\text { FGFR inhibitor }\end{array}$ & Day 4 in protocol & $\begin{array}{l}\text { IsII, Nkx2.5, KDR, CD3I, } \\
\text { cTNT, MEF2C, TBX5, } \\
\text { TBX20, Gata4 }\end{array}$ \\
\hline $\begin{array}{l}\text { Multipotent cardiovascular } \\
\text { progenitor }^{\prime 2}\end{array}$ & $\begin{array}{l}\text { MEF feeders, VEGFA } \\
\text { and DKKI }\end{array}$ & Day 6 in protocol & $\begin{array}{l}\text { KDR }^{\text {low }} \text {, c-kit-, CDI66, } \\
\text { cTNT, MLC2A, SMA, } \\
\text { calponin, CD3I }\end{array}$ \\
\hline
\end{tabular}

Abbreviations: Nkx2.5, NK2 homeobox 5; FOG2, zinc finger protein, multitype 2; cTnT, cardiac troponin T; MEF2C, myocyte enhancer factor 2C; cTnl, cardiac troponin l; IsII, islet-I; GATA4, GATA-binding protein 4; KDR, kinase insert domain receptor; $\alpha$ SMA, $\alpha$ smooth-muscle actin; $\alpha$ MHC, $\alpha$-myosin heavy chain; PDGFR $\alpha$, platelet-derived growth-factor receptor $\alpha$; BMP4, bone morphogenetic protein 4; FGF, fibroblast growth factor; MEF, mouse feeder cells; VEGFA, vascular endothelial growth factor A; DKKI, dickkopf I homologue. 
a significant increase in cell retention ( $90 \%$ vs $64.9 \%$ ) at 2 months posttransplantation using magnetic resonance imaging (MRI) to detect iron oxide labeling of cells; this technique also resulted in a significantly greater vascular density in the infarcted area by immunohistochemical analysis of von Willebrand factor when compard to transplantation of cells alone (225 \pm 74 units $/ \mathrm{mm}^{2}$ vs $55 \pm 7$ units $\left./ \mathrm{mm}^{2}, P<0.01\right) .{ }^{16}$ The functional impact on LVEF was not reported. ${ }^{16}$

Combination therapy of cardiac cell types has also been attempted in a porcine model of myocardial ischemia. iPSCs derived from human dermal fibroblasts were differentiated into cardiomyocytes, endothelial cells, and smooth-muscle cells, and were transplanted ( 2 million cells each) along with a fibrin patch loaded with gelatin microspheres encapsulating insulin-like growth factor (IGF) into a porcine model of myocardial ischemia. This procedure resulted in a reduction of host cardiomyocyte apoptosis and a significant increase in ejection fraction (54.6\% vs $43.4 \%$ patch alone). ${ }^{17}$

In large animals, iPSCs have been generated from pig fibroblasts, ${ }^{18}$ pig stromal cells, ${ }^{19}$ bovine fibroblasts, ${ }^{20}$ and canine adipose tissue and skin. ${ }^{21}$ There is little functional data, however, regarding the syngeneic or allogeneic use of these cells for treatment of myocardial infarction.

\section{Considerations for transplantation of iPSCs}

iPSCs have potential as a treatment for myocardial infarction; however, further study is warranted to fully investigate safety concerns and to understand the inherent characteristics of iPSCs that may render them different from other cell types considered for transplantation therapy. Although there were no adverse events associated with the transplantation of iPSCs in the studies presented here, they remain a concern due to the potential for formation of teratomas. Induction of pluripotency is not always stable after viral delivery, and the process of reprogramming itself may be associated with gene-expression differences that distinguish iPSCs from embryonic stem cells. iPSC cell lines have, on average, six protein sequence-changing point mutations per cell line, ${ }^{22}$ with approximately $74 \%$ of mutations occurring during the process of reprogramming. ${ }^{23}$ These differences contribute to transplantation safety concerns, and may also play a role in increased immunogenicity; undifferentiated iPSC induce a more pronounced $\mathrm{T}$ cell-mediated immune response when compared with embryonic-derived stem cells. ${ }^{24}$ This immunogenicity is controversial and may be caused by the method of pluripotency induction or the fact that these cells were introduced in an undifferentiated state. ${ }^{25}$
Not all types of iPSC are the same due to differences in reprogramming methods, or tissue of origin. iPSCs retain an epigenetic memory of their tissue of origin in their epigenome. These unique DNA methylation patterns result in an increased tendency for certain genes to be transcribed ${ }^{26}$ and an elevated tendency towards redifferentiation back into the original cell type. A prime example of this phenomenon can be found in postnatal cardiomyocyte-derived iPSCs, which when dedifferentiated have an increased tendency towards cardiac redifferentiation. ${ }^{27}$ This epigenetic memory may be a roadblock in using reprogrammed cells from readily accessible tissues such as the skin as a therapy for myocardial infarction. If iPSCs are to be differentiated into either cardiac progenitors or differentiated cardiomyocytes prior to transplantation, methods to optimize the differentiation protocol must be implemented to ensure that the differentiated cell populations fully mimic the desired cell type, both genetically and epigenetically. Ongoing work to address these challenges will continue to advance the potential for iPSCs to become a promising therapy for myocardial regeneration.

\section{Endogenous cardiac stem cells}

Endogenous cardiac stem cells (CSCs) derived from the heart tissue itself hold great promise for cardiac regeneration. Endogenous cardiac progenitors have been defined on the basis of surface phenotype (Table 2). However, the optimal cell or combination of cells for transplantation within this group is still not well defined. A direct functional comparison of these distinct CSC populations in vivo will be needed to identify the optimal stem cell type(s) for myocardial regeneration.

\section{c-kit ${ }^{+}$cardiac stem cells}

One of the most well-known types of stem cells, isolated by surface-antigen enrichment, are the c-kit ${ }^{+} \mathrm{CSCs}$. These cells are a heterogeneous population characterized by the absence of CD34, CD31 (platelet/endothelial cell-adhesion molecule), kinase insert domain receptor (KDR), and CD45 (leukocyte common antigen). They have the ability to form all three cardiac lineages in vitro. Ckit + cardiac stem cells have low to moderate levels of cardiac transcription factors such as gata binding protein 4 (0.4-47.5\% positive) and cardiac-specific homeo box, $\mathrm{Nkx} 2.5$ ( $0.43-24.3 \%$ positive). ${ }^{28,29}$

When transplanted into the infarcted rat myocardium, human $\mathrm{c}-\mathrm{kit}^{+}$cardiac progenitors form a band of regenerated myocardium. Enhanced green fluorescent protein (EGFP) labeling of injected c-kit ${ }^{+}$cells confirmed the presence of $\mathrm{EGFP}^{+}$cells in all three cardiac lineages, suggesting 
Table 2 Human endogenous cardiovascular stem cells and their markers

\begin{tabular}{|c|c|}
\hline c-kit ${ }^{+}$cardiac stem cells ${ }^{28}$ & $\begin{array}{l}\text { Negative for: CD45, CD34, CD3I, } \\
\text { and KDR }\end{array}$ \\
\hline & Positive for: c-kit \\
\hline Vascular c-kit ${ }^{+}$stem cells ${ }^{32}$ & $\begin{array}{l}\text { Negative for: CD34, CD } 45, C D I 33 \text {, } \\
\alpha S A \\
\text { Positive for: c-kit, KDR, low levels } \\
\text { of CD3I and TGF- } \beta \text { I }\end{array}$ \\
\hline Myogenic c-kit ${ }^{+}$stem cells ${ }^{32}$ & $\begin{array}{l}\text { Negative for: CD34, CD45, CDI33, } \\
\alpha \text {-SA, CD3I, TGF- } \beta \text { I, KDR }\end{array}$ \\
\hline Cardiospheres ${ }^{53}$ & $\begin{array}{l}\text { Negative for: CD34, CD45 } \\
\text { Positive for: c-kit (core), CD3I } \\
\text { (periphery), CD90, CDI05 } \\
\text { (periphery), } \alpha M H C \text { (periphery), } \\
\text { cTnl (periphery), CD I33 } \\
\text { (periphery), MDR-I (periphery), } \\
\text { connexin } 43, \text { Nkx2.5 } \\
\text { (core), desmin (core) }\end{array}$ \\
\hline $\begin{array}{l}\text { Cardiosphere-derived cells } \\
(C D C s)^{57}\end{array}$ & $\begin{array}{l}\text { Negative for: CD3I, CD34, CD } 45 \text {, } \\
\text { CD I33 } \\
\text { Positive for: CD29, CD I05, CD90'low, } \\
\text { c-kit }{ }^{\text {low }}\end{array}$ \\
\hline Mesangioblasts ${ }^{62}$ & $\begin{array}{l}\text { Negative for: CD } 45, \text { CDI33, IsII } \\
\text { Positive for: CD3I, CD } 34, \text { CD } 44 \text {, } \\
\text { ckit, CDI } 46, n k \times 2.5, \text { GATA-4, MEF2A } \\
\text { Tbx2, Tbx5 }\end{array}$ \\
\hline $\mathrm{BCRP}^{+}$side-population cells ${ }^{63}$ & $\begin{array}{l}\text { Negative for: c-kit, CD3I, Sca-I, } \\
\text { Oct3/4, SSEA-3, SSEA-4 } \\
\text { Positive for: Nkx2.5, } \alpha \text { SA }\end{array}$ \\
\hline $\mathrm{IsI}^{+}$cardiac progenitors $^{50}$ & Positive for: IsI I, c-kit (in fetus) \\
\hline
\end{tabular}

Abbreviations: BCRP, breast cancer-resistant protein; KDR, kinase insert domain receptor; $\alpha S A$, sarcomeric alpha actin; SSEA, stage-specific embryonic antigen; TGF- $\beta$ I, transforming growth factor beta I; GATA4, GATA-binding protein 4; MDRI, multidrug resistance protein I; $\alpha M H C$, alpha myosin heavy chain; IsII, Islet I; cTnl, cardiac troponin I; Nkx2.5, NK2 homeobox 5; MEF2A, myocyte enhancer factor 2A; Tbx, T-box.

differentiation; however, the possibility that this was the result of cell fusion was not addressed. ${ }^{30}$ Pretreatment with ephrin A1 (a cell-signaling molecule that plays a role in cell adhesion, movement, division, and differentiation) prior to CSC transplantation improved regeneration capacity. This resulted in greater cell retention, enhanced speed of CSC migration, decreased arrhythmias, a 37\% decrease in infarct size (twofold greater than CSCs alone), and a significant increase in ejection fraction and left ventricular developed pressure. ${ }^{31}$

Given that the isolation of c-kit ${ }^{+}$CSCs is dependent solely on the expression of c-kit and absence of CD45 as a basis for CSC enrichment, these cells have an inherent heterogeneity. Several studies have identified subpopulations of c-kit ${ }^{+}$progenitors with differences in functional capacity. Bearzi et al identified two different subpopulations of

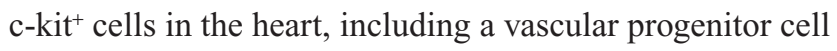
that is c-kit ${ }^{+} \mathrm{KDR}^{+}$(found in epicardial coronary arteries, arterioles, and capillaries) and a myogenic progenitor that is

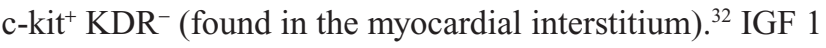
receptor (IGF1R) has also been used to differentiate between c-kit ${ }^{+}$progenitor populations. ${ }^{33}$ Human c-kit ${ }^{+}$IGF1R ${ }^{+}$cells were most beneficial for cardiovascular regeneration. When transplanted into the infarcted myocardium of immunosuppressed rats, c-kit ${ }^{+}$cells expressing IGF1R significantly increased infarcted tissue regeneration $\left(12 \mathrm{~mm} \mathrm{IGF1R^{+ }}\right.$ CSCs vs $\left.7 \mathrm{~mm} \mathrm{IGFIR}^{-} \mathrm{CSCs}\right)$. Pretreatment with IGF2 further improved tissue regeneration $(15 \mathrm{~mm})$ and ejection fraction. ${ }^{33}$ Another study delineating c-kit ${ }^{+}$CSC subpopulations discovered that several $\mathrm{c}-\mathrm{kit}^{+}$progenitors divide using asymmetric chromatid segregation, and when dividing, one daughter cell receives the synthesized copy of DNA (here termed "copy" CSCs) while the other daughter cell retains the template strand of DNA (here termed "template" CSCs). Transplantation of c-kit template CSCs almost completely regenerated the infarct-wall thickness $\left(60 \mathrm{~mm}^{3}\right.$ using template CSCs vs $25 \mathrm{~mm}^{3}$ using copy CSCs). Animals transplanted with template CSCs had a greater recovery of systolic pressure, developed pressure, and positive and negative $\mathrm{dP} / \mathrm{dt}$, which contributed to an attenuation of diastolic wall stress when compared to animals transplanted with copy CSCs. ${ }^{34}$ Overall, these results suggest that the optimal progenitors may be less heterogeneous than the total population of c-kit ${ }^{+}-$ enriched stem cells.

Other considerations for transplantation include the ability to isolate $\mathrm{c}-\mathrm{kit}^{+}$progenitors for syngeneic use in clinical

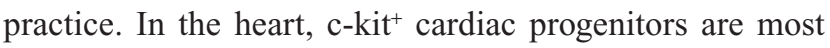
abundant in the atria, ${ }^{35-38}$ followed by the left ventricle, right ventricle, apex, and atrioventricular junction. ${ }^{38}$ Disease and sex affect the distribution of cells; ${ }^{37-39}$ females tend to have a greater number of c-kit ${ }^{+}$cardiac progenitors. ${ }^{37}$ Medical history, including the use of $\beta$-blockers, smoking, atrial fibrillation, and prior myocardial infarction, can influence the frequency of c-kit ${ }^{+}$progenitors in the heart. ${ }^{40}$ Failing hearts have a roughly fourfold increase in c-kit ${ }^{+}$progenitor cells, and it has been shown that approximately $80 \%$ of these cells coexpress CD $45 .{ }^{41}$ Although the majority of these cells express CD45, this population as a pool was able to differentiate effectively into cardiomyocytes in vitro. Interestingly, while failing hearts have increased numbers of $\mathrm{c}-\mathrm{kit}^{+}$progenitors, age has been correlated with a decrease in the number of functional progenitors. This discrepancy could be accounted for by the fact that there are several subpopulations of c-kit ${ }^{+}$ progenitors, and in failing hearts, even though there are more cardiac progenitors, those with the greatest capacity to heal the myocardium may be exhausted. 
Several changes occur within the $\mathrm{c}-\mathrm{kit}^{+}$progenitor population as a person ages. After the first month of life, for example, there is a dramatic decrease in the total number of c-kit ${ }^{+}$CSCs. ${ }^{42}$ Even well into adulthood, age remains a factor in the yield of c-kit ${ }^{+}$CSCs that can be obtained from a tissue biopsy. ${ }^{43}$ Advancing age also contributes to increased senescence of c-kit ${ }^{+}$stem cells, as demonstrated by telomere shortening, attenuated telomerase activity, telomere dysfunction-induced foci, and the expression of $\mathrm{p} 21^{\mathrm{Cip} 1}$ and p16 ${ }^{\text {INK4a }} \cdot{ }^{44}$ To combat this senescent phenotype, $\mathrm{c}^{-\mathrm{kit}^{+}}$cardiac progenitors have been genetically engineered to overexpress genes such as $\beta$-adrenergic receptor kinase (which enhanced the viability, proliferation, and survival of CSC $),{ }^{45}$ or pim-1 (resulting in increased cell engraftment, reduced infarct size, and increased hemodynamic performance at 20 weeks postmyocardial infarction) ${ }^{46}$

\section{Is| I+ cardiac progenitors}

During development of the heart, Is $11^{+}$progenitors play a crucial role in the creation of the right ventricle, atria, and outflow tract. ${ }^{47}$ Is $11^{+}$cells are multipotent progenitors that are able to differentiate into all three cardiovascular lineages. ${ }^{48}$ The Is $11^{+}$cell may therefore be the optimal progenitor cell for cardiac regeneration. However, the expression of Isll in endogenous cardiovascular progenitors is closely correlated with age. Neonatal and fetal tissues have abundant levels of Isl1 $1^{+}$progenitor populations, yet with increasing age Isl1 is reduced to low or reportedly nonexistent levels. ${ }^{49}$ Furthermore, the surface characteristics of Isl1expressing cells have not been well defined..$^{50}$ Most studies identifying Isl1 progenitors are lineage-tracing studies. In considering the benefits of distinct progenitors for cardiac regeneration, the fact that these cells are rare in the adult myocardium may make them difficult to use for autologous transplantation. The potential for human $\mathrm{Isl}^{+}$cardiovascular progenitors to be isolated and expanded for therapeutic use still exists in neonates where the cells are abundant. Further work is needed to study their therapeutic role and potential value for clinical use in neonates.

\section{Cardiospheres and cardiosphere-derived cells}

Cardiospheres generated from endogenous cardiovascular cells have been extensively used for regenerating the myocardium. Cardiospheres consist of a heterogeneous population of cells that are exclusively heart-derived ${ }^{51}$ and have been studied in three different formats. Primary cardiospheres are derived from endomyocardial biopsies that are partially digested enzymatically, then plated as explants on fibronectin-coated dishes. After several days in culture, small phase-bright cells migrate out from the explants. Once confluent, these cells are harvested and plated in poly-Dlysine coated dishes in the presence of cardiosphere-forming medium. The cells that float up in sphere-like structures are termed primary cardiospheres. ${ }^{52}$ These cells are characterized by a core of cells that are positive for c-kit, nkx2.5, and desmin (Table 2). ${ }^{53}$ When passaged as monolayers, the cells form CDCs. CDCs exposed to epidermal growth factor (EGF) can reform cardiospheres. These cells are termed secondary cardiospheres. ${ }^{54}$

In vitro, cardiospheres (when in low serum) secrete a panel of factors, including vascular endothelial growth factor (VEGF), hepatocyte growth factor, and IGF1, whereas CDCs and secondary cardiospheres only secrete VEGF. ${ }^{54}$ The heterogeneity of primary cardiospheres results in a microenvironment that mimics the stem cell niche, with a periphery of supporting cell populations whose paracrine role enhances regeneration. ${ }^{53}$ The proteomics of both the spherical aggregates and adherent cells have been analyzed, and interestingly it is the cardiospheres that, when differentiated, express higher levels of troponin I (cTnI).$^{55}$ Cardiospheres usually have a percentage of cells that are $\mathrm{CD} 45^{+}$; however, these cells are not essential for cardiosphere formation ${ }^{56}$ and their role is unclear. Although cardiospheres seem to have functional advantages, CDCs are more widely used, due to safety concerns associated with the administration of cardiospheres via intracoronary infusion and the potential for adverse events, such as a microembolism.

A comparison of CDCs, bone marrow-derived mesenchymal stem cells, adipose tissue-derived mesenchymal stem cells, and bone marrow-derived mononuclear cells showed that CDCs had a superior paracrine effect when injected into severe combined immunodeficient mice, as shown by a significant increase in ejection fraction associated with the use of CDCs versus other cell types. ${ }^{57}$ The further addition of exogenous paracrine factors such as EGF provides an additive effect on cardiac regeneration over the benefit that can be achieved by CDCs alone. In vitro analysis of the functionality of CDCs in response to growth factors (including EGF, VEGF, IGF, basic fibroblast growth factor [bFGF], hepatocyte growth factor, transforming growth factor, and platelet-derived growth factor) showed that EGF significantly improved the migration, proliferation, and wound healing of CDCs and additionally elevated cTnI and myosin heavy-chain expression. ${ }^{58}$ Challenges to cell retention have been addressed by administration of CDCs embedded in various formulations of hydrogel. This approach increases 
cell engraftment, LVEF, and viable tissue at 3 weeks after transplantation. ${ }^{59}$ Cardiac progenitor cell sheets provide an alternative approach for increasing engraftment and function, as demonstrated by an improvement in end-diastolic pressure, end-systolic volume, end-diastolic volume, and load-independent systolic function. ${ }^{60}$

There are several things to consider when using these cells for regenerating the heart. First of all, inherent in the cardiosphere isolation technique is the heterogeneity of these cells, which in clinical practice may lead to a varied outcome. Similar to other CSCs, age is correlated with functionality. Human neonatal CDCs expressed higher levels of c-kit, KDR, and Is11, had an enhanced cardiomyogenic differentiation potential, and when transplanted in vivo resulted in a greater improvement in ejection fraction and secretion of angiogenic factors when compared to transplantation of adult CDCs. ${ }^{49}$

In a mouse model of MI, both syngeneic and allogeneic CDCs, without immunosuppression, were able to significantly improve infarct size, infarcted wall thickness, and ejection fraction after transplantation, compared to controls. ${ }^{61}$ The number of retained allogeneic cells dropped significantly at 3 weeks due to isolated events of cellular rejection, without a significant depreciation in functional improvement, suggesting that these cells could hypothetically be transplanted in an allogeneic setting. Paracrine mechanisms are likely to benefit during this time frame; however, long-term benefit in the absence of sufficient numbers of cardiac progenitors is questionable.

\section{Other endogenous progenitor populations}

Although the most widely studied progenitor populations in the human heart are the c-kit ${ }^{+} \mathrm{CSCs}$, Isl1 ${ }^{+} \mathrm{CSCs}$, and CDCs, several other stem cell populations in the heart are capable of cardiomyogenic differentiation. Mesangioblasts can be isolated from the human heart, and are phenotypically similar to other cardiac progenitors (Table 2), but whether or not these cells originate in the heart is debated. Evidence suggests that this population may have exhausted their regenerative potential in patients with disease such as left ventricular hypertrophy. ${ }^{62}$ In addition to mesangioblasts, a population of cardiac side-population progenitors has been proposed to be in the heart and involved in cardiac regeneration. ${ }^{63}$ This population is characterized by the presence of breast cancer-resistance protein and the absence of both c-kit and CD31. They are induced in the ischemic myocardium, but whether or not they play a role in heart regeneration, have a redundant function, or work synergistically with other cardiac progenitor populations is not well understood.
The diversity of the endogenous cardiac progenitor population suggests that it is crucial to define clearly the differences between these populations to better understand their relative regenerative potential. There has been some debate as to whether or not several known populations of stem cells represent overlapping progenitor types. Koninckx et al compared cardiosphere-derived cells and c-kit ${ }^{+}$cells using surface-antigen and gene-expression analysis of undifferentiated and differentiated cells. This group concluded that no detectable differences existed when comparing c-kit ${ }^{+}$cells and CDCs, and that these cells may in fact be the same cell. ${ }^{64}$ Recent work by Cheng et al suggests that the percentage of CDCs that were c-kit ${ }^{+}$was not relevant for the observed improvement in viable mass and scar size. ${ }^{65}$ These conflicting views underline the importance of carefully defining the various cardiac stem cell types within the heart in order to clarify their respective roles and define the optimal progenitor for transplantation.

\section{Endogenous progenitors in large animals}

Studies in large-animal models of heart failure and stem cell delivery are severely lacking in the wake of the large number of rodent studies designed to test new treatments for heart failure. The ability to translate new findings in rodents into effective therapies that will enhance clinical practice will require additional studies in large animals. There are several promising large-animal models of heart failure; each has its own drawbacks, and there is no perfect model of human anatomy. ${ }^{66}$

\section{Cell types}

There are several different types of endogenous CSCs that have been identified in experimental large-animal models and in humans. CSCs have been isolated from dogs, pigs, and most recently sheep. The two most commonly used methods of stem cell isolation in large animals are the cardiosphere method and c-kit ${ }^{+}$enrichment.

CDCs isolated from percutaneous endomyocardial biopsies have been obtained from pigs and dogs. Pig and human CDCs express similar markers (Table 2) and can differentiate in vitro into electrically functional myocytes. ${ }^{52}$ Cardiovascular progenitors isolated as either cardiospheres that express c-kit, paired box 6 , and proliferating cell nuclear antigen ${ }^{67}$ or as pooled c-kit ${ }^{+}$cardiac progenitors have been reported in the canine model. c-kit ${ }^{+}$cells in dogs differentiate into cardiomyocytes with a higher efficiency when compared with cells isolated on the basis of multidrug resistance protein 1 and spinocerebellar ataxia 1 expression. ${ }^{68}$ 
Our laboratory has taken the approach of isolating endogenous cardiovascular progenitor cells as clones to define the phenotype and function of the most promising cells for cardiovascular repair. We have recently identified several individual cellular phenotypes within the endogenous cardiovascular stem cell population in sheep and have compared these results to our findings in humans. Four distinct subpopulations of cardiac progenitors exist in the heart of neonatal sheep, some of which lack the expression of c-kit. ${ }^{69}$ These populations were defined as $\mathrm{CD} 105^{+}$stage-specific

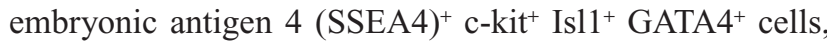
$\mathrm{CD}_{105^{+}} \mathrm{SSEA}^{+}{ }^{+} \mathrm{c}-\mathrm{kit}^{+} \mathrm{Is} 11^{+} \mathrm{GATA}^{-}{ }^{-}$cells, $\mathrm{CD} 105^{+} \mathrm{SSEA}^{-}$ c-kit $^{-}$Isl1 ${ }^{+}$GATA4 ${ }^{-}$cells, and CD $105^{+}$SSEA4 $^{-}$c-kit $^{+}$Isl1 $^{+}$ GATA4 ${ }^{-}$cells. Interestingly, all progenitor clones expressed Isl1 (Figure 1). Comparable clones isolated from human neonates in our laboratory were not uniformly Is $11^{+}$. Overall, the progenitors that we isolated from the sheep heart exhibit similar phenotypic features when compared with human cardiac progenitors. Defining the functionality of clonal cardiac progenitor populations will be a component of ongoing work in our laboratory.

\section{Functional benefits in large animals}

At the present time, CDCs are the most extensively studied endogenous cardiac progenitors in large-animal models of MI. CDCs have been administered to both healthy and infarcted pigs at 4 weeks after MI through intracoronary infusion. ${ }^{70}$ Due to the relative size of CDCs $(21 \mu \mathrm{m})$ in comparison to the capillary luminal diameter $(7-10 \mu \mathrm{m})$, cell infusion in high numbers is associated with microvascular occlusion and infarct. The number of cells that can be infused safely is limited to $\leq 10^{7}$. Functional studies done at 8 weeks postinfusion showed that after injection of $10^{7} \mathrm{CDCs}$, there were no significant differences in left ventricular mass, infarct size, end-diastolic volume, end-systolic volume, LVEF, or enddiastolic pressure. Significant differences were found only in pressure change $(\mathrm{dP} / \mathrm{dt})$ maximum, and $\mathrm{dP} / \mathrm{dt}$ minimum. This modest benefit was attributed to the low engraftment of cells. ${ }^{70}$ In an attempt to increase engraftment, cells were injected directly into the myocardium (rather than intracoronary infusion) in a later study. Cardiospheres or CDCs were injected at 4 weeks post-MI through an open-chest surgery technique that included 20 intramyocardial injections of 0.5 million cells. ${ }^{71}$ The injection of either cardiospheres or CDCs preserved LVEF, which in the placebo group deteriorated approximately seven percentage points during the 8-week observation period. However, the cardiospheres had superior benefit (over CDCs) in terms of a significantly higher end-systolic elastance, significantly lower delta enddiastolic pressure, and greater apical septal thickening. ${ }^{71}$ The long-term retention of CDCs at 8 weeks postinjection was confirmed by the presence of lac $Z^{+}$-labeled cardiomyocytes in two animals that received lacZ $Z^{+}$-labeled CDCs. It was not determined whether these labeled cardiomyocytes originated as a consequence of direct differentiation or cell fusion. In this study, there was an overall $34 \%$ mortality rate associated with the creation of MI and engraftment of cells. The injection of a greater number of cells did not necessarily increase engraftment or benefit, and in fact the lowest dose of cells ( 0.5 million cells) was associated with the highest percentage of engraftment in the border zone. Additionally, there was no engraftment when cells were injected directly into the infarct scar. This work has served as the basis for the "Intracoronary cardiosphere-derived cells for heart regeneration after myocardial infarction" (CADUCEUS) clinical trial. ${ }^{72}$

\section{Human cells in large animals}

Several studies have used human CDCs in large animal models. Takehara et al transplanted human CDCs in a cyclosporin A-immunosuppressed pig. This study compared the efficacy of human bone marrow-derived mesenchymal stem cells to human CDCs with the addition of bFGF, which was administered in a slow-release hydrogel. ${ }^{73}$ Engraftment was measured using superparagmagnetic iron oxide nanoparticle labeling for tracking cells using MRI. In this study, it was found that both bFGF alone and mesenchymal stem cells cotransplanted with bFGF showed an equal, nonsignificant improvement in LVEF ( four-percentage-point increase), demonstrating no additive effect at 4 weeks postinjection. In contrast, bFGF had an additive effect when combined with CDCs, resulting in a significant increase in LVEF (38.4\% vs $30.1 \%$ ) and regional wall motion ( $58.5 \%$ vs $46.2 \%$ ) compared to baseline. Fluorescence in situ hybridization analysis confirmed the presence of labeled cardiomyocytes at 4 weeks post-MI; $33 \%$ of labeled cardiomyocytes were newly differentiated (not the result of cell fusion), as shown by immunohistochemical colocalization of the human $Y$ chromosome with sarcomeric $\alpha$ actin and an absence of the porcine genome. In comparison, less than $10 \%$ of the cardiomyocytes were the result of direct differentiation in pigs that received bone marrow-derived mesenchymal cells, suggesting a higher level of direct regeneration in pigs treated with CDCs at 4 weeks postinjection. Due to the short-term nature of this study, however, the significance of these results on long-term functional improvement after transplantation is unknown. ${ }^{73}$ 
A
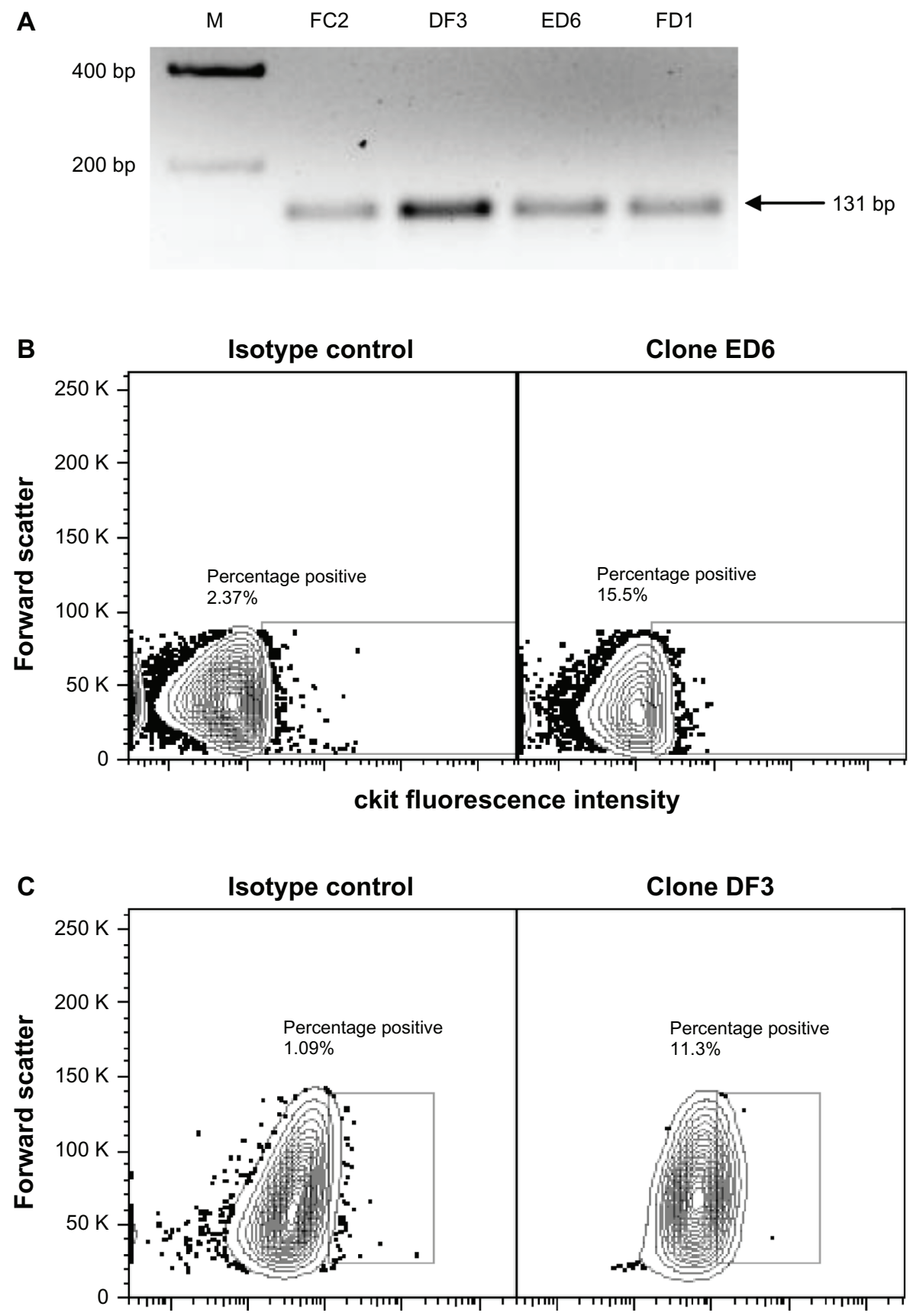

SSEA-4 fluorescence intensity

Figure I (A-C) Expression of IsII, c-kit and SSEA4 on neonatal sheep cardiovascular progenitor cell clones. Neonatal sheep cardiovascular progenitor cell clones express IsII, as identified using PCR. Representative clones expressing transcripts for IsII are shown (A, size I3I bp). Flow cytometry was used to identify cardiovascular progenitor clonal populations on the basis of additional markers. Shown are representative c-kit ${ }^{+}(\mathbf{B})$ and SSEA4 ${ }^{+}(\mathbf{C})$ neonatal sheep cardiovascular progenitor cell clones. Abbreviations: IsII, Islet I; SSEA4, stage-specific embryonic antigen 4; PCR, polymerase chain reaction.

\section{Considerations for transplantation of endogenous CSCs}

Experiments done in large-animal models using endogenous cardiac progenitors as a therapy for MI have been promising, with no reports of tumors. However, further studies are needed to decrease mortality (associated with creation of MI) and improve ejection fraction after cell therapy.
Both intracoronary infusion of cells and intramyocardial injection provide modest benefits, which may be limited as a consequence of low engraftment. ${ }^{70}$ Intramyocardial injection (through open-chest surgery) seems to be preferable to intracoronary infusion in terms of functional benefits and engraftment; however, due to the invasive, high-risk nature of this procedure, it may have limited use in a clinical setting. 
CDCs act mainly through a paracrine effect that diminishes significantly over time as cell number decreases. Lessons learned about cellular mechanisms of myocardial repair and regeneration in rodents need to be implemented in large animals to optimize the relative contribution of newly introduced progenitors. This involves not only activating endogenous progenitors ${ }^{74,75}$ but also recruiting progenitors from sources outside the heart for cardiovascular repair. A combination of cell types and activating factors embedded in an engraftment-promoting medium seems to hold the most promise for regeneration; however, the optimal combination has yet to be determined.

\section{Current clinical trials}

Cell-based therapies to regenerate the damaged myocardium using endogenous cardiac progenitors have been used in the recently completed CADUCEUS and "Administration of cardiac stem cells in patients with ischemic cardiomyopathy" (SCIPIO) clinical trials (Table 3). Interestingly, the two trials had very different functional results. The fully randomized CADUCEUS trial, led by Eduardo Marban, consisted of 25 patients (17 treatment, 8 control) who underwent endomyocardial biopsy less than one 1 month post-MI to create CDCs, which were administered through intracoronary injection. This procedure caused a reduction in scar mass (12 g decrease), increased viable heart mass (22.5 g increase), and improved regional contractility and regional systolic wall thickening. However, at 12 months, functional measurements of end-diastolic volume, end-systolic volume, and LVEF did not differ significantly between groups. ${ }^{76}$ The heterogeneity of CDCs may account for this lack of functional improvement. Linear regression demonstrated that the percentage of CDCs expressing CD90 correlated negatively to outcome. Interestingly, the percentage of c-kit ${ }^{+}$cells (range $0.3 \%-7.2 \%$ ) was not correlated with scar size or increase in viable mass. ${ }^{65}$

A total of 33 patients (20 treatment, 13 control) were involved in the SCIPIO trial, led by Roberto Bolli. ${ }^{77}$ In this study, endogenous c-kit ${ }^{+}$cardiac progenitors were isolated from the right atrial appendage, passaged to sufficient numbers, and injected (maximum $10^{6}$ cells) into the surgical graft during coronary artery bypass grafting surgery at least 4 months post-MI. At 2 years after CSC infusion, LVEF increased from a baseline of $29.7 \%$ to $41.7 \%$, with concomitant improvements in left ventricular viable mass $(12.2 \%$ increase) and infarct size (15.7\% decrease). Nonsignificant improvements were reported in the control populations. Within the treated population, measures such as the New York Heart Association classification decreased significantly after 2 years $(0.92$ compared with a control decrease of 0.17), and the Minnesota Living With Heart Failure Questionnaire score also decreased significantly at 2 years (26.9-point decrease compared to the control decrease of 5.2 points).

A third clinical trial, led by Hiroaki Matsubara in Japan, titled "Autologous human cardiac-derived stem cell to treat ischemic cardiomyopathy" (ALCADIA), is still in progress. This trial is designed to test the efficacy of transplanting both CSCs from endomyocardial biopsies and a hydrogel infused with FGF. Injected cells expanded for this trial expressed CD105, CD90, CD29, NANOG, OCT4, and GATA4 and were negative for CD45. Six patients are currently enrolled in this study. All patients have been enrolled in the cell-treated group. Preliminary data after combination therapy at 6 months reported an improvement

Table 3 Clinical trials using endogenous cardiac progenitors

\begin{tabular}{|c|c|c|c|}
\hline Clinical trial & ALCADIA $^{78}$ & CADUCEUS $^{76}$ & SCIPIO ${ }^{77}$ \\
\hline \multirow[t]{2}{*}{ Cell type } & Autologous CDC with & Autologous CDC & Autologous c-kit ${ }^{+}$ \\
\hline & FGF hydrogel & & cardiac derived cells \\
\hline Number of treated patients & 6 & 17 & 20 \\
\hline \multirow[t]{3}{*}{ Inclusion criteria } & LVEF I5\%-35\%, ischemia & LVEF $25 \%-45 \%,<30$ days & LVEF $<40 \%$, history \\
\hline & cardiomyopathy, past history & post-MI, history of angioplasty, & of Q-wave MI, scheduled \\
\hline & of $\mathrm{HF}$ & area of regional dysfunction & for $C A B G$ within 2 weeks \\
\hline Cells collected & No data & $<30$ days after $\mathrm{MI}$ & 3-5 months post-MI \\
\hline Number of injected cells & 0.5 million cells $/ \mathrm{kg}$ & $12.5-25$ million & $0.5-I$ million \\
\hline Time frame & 6 months & I year & 2 years \\
\hline \multirow[t]{2}{*}{$\Delta \mathrm{LVEF}$} & $9.1 \%$ (3-D echo) & $5.4 \%(\mathrm{MRI}), \mathrm{NS}$ & $12.0 \%(3-D$ echo) \\
\hline & $12.1 \%(\mathrm{MRI})$ & & $12.1 \%(\mathrm{MRI})$ \\
\hline Increase in viable tissue & No data & $22.6 \mathrm{~g}$ & $12.20 \%$ \\
\hline Decrease in scar mass & No data & $12 \mathrm{~g}$ & $15.7 \mathrm{~g}$ \\
\hline Wall motion score & -10.6 & No data & -3.92 \\
\hline
\end{tabular}

Abbreviations: LVEF, left ventricular ejection fraction; MI, myocardial infarction; CDC, cardiosphere-derived cells; FGF, fibroblast growth factor; CABG, coronary artery bypass graft surgery; HF, heart failure; NS, nonsignificant; MRI, magnetic resonance imaging. 
in LVEF (from $26.7 \%$ to $35.8 \%$ by $3-\mathrm{D}$ echo and $22.6 \%$ to $34.7 \%$ by MRI), as well as a decrease in infarct volume by MRI (from $23 \%$ to $19.7 \%$ ) and a concomitant decrease in wall motion score (from 17.2 to 6.6 ). ${ }^{78}$ Interestingly, exercise capacity also improved, as demonstrated by an improvement of maximum $\mathrm{O}_{2}$ consumption (12.2 to 16.7). Comparison of these outcomes with a control population has yet to be reported.

Several promising clinical trials using endogenous cardiac progenitors are ongoing, but the results have not been published. The clinical trial "Transcoronary infusion of cardiac progenitor cells in patients with single ventricle physiology" or TICAP (NCT01273857), ${ }^{79}$ led by Hidemasa Oh, is designed to treat hypoplastic left heart syndrome in patients less than 6 years old. A growing number of children with hypoplastic left heart syndrome need a heart transplant due to end-stage organ failure. Fourteen patients have been enrolled in this safety and feasibility trial of transcoronary infusion of cardiac progenitors. Patients will receive 0.3 million $/ \mathrm{kg}$ of autologous cardiac progenitor cells via intracoronary delivery 1 month after cardiac surgery. Patients will then be monitored for 3 months to 1 year after cell transplantation.

The phase I/II "Allogeneic heart stem cells to achieve myocardial regeneration" (ALLSTAR) trial (NCT01458405) $)^{80}$ is designed to test the safety of allogeneic CDCs. This study, led by Eduardo Marban, is currently recruiting participants (with LVEF $<45 \%$ ) and expects an enrollment of 274 patients. Cells will be transplanted $<3$ months or 3-12 months after myocardial infarction to assess the ideal time frame for cell delivery. This is the first clinical trial to investigate the allogeneic use of endogenous CSCs in humans.

\section{Conclusion}

Early clinical trials using endogenous cardiac progenitors underscore the promise of cell-based therapies for cardiovascular repair. It is evident, based on this new data, that cell transplantation results in an increase in viable tissue and an improvement in functional outcome. The majority of completed and ongoing clinical trials using endogenous cardiac progenitors are preliminary and thus do not have matched analysis of carefully randomized controls. Further optimization of methods to increase engraftment and regeneration, such as selection of cell types for treatment and growth-factor enhancement, will improve upon these initial results. As work in the field progresses, regenerating the injured myocardium through stem cell-based therapies may become feasible as a therapeutic option for future generations.

\section{Disclosure}

The authors report no conflicts of interest in this work.

\section{References}

1. Takahashi K, Tanabe K, Ohnuki M, et al. Induction of pluripotent stem cells from adult human fibroblasts by defined factors. Cell. 2007;131(5):861-872.

2. Novak A, Shtrichman R, Germanguz I, et al. Enhanced reprogramming and cardiac differentiation of human keratinocytes derived from plucked hair follicles, using a single excisable lentivirus. Cell Reprogram. 2010; 12(6):665-678.

3. Haase A, Olmer R, Schwanke K, et al. Generation of induced pluripotent stem cells from human cord blood. Cell Stem Cell. 2009;5(4): 434-441.

4. Giorgetti A, Montserrat N, Aasen T, et al. Generation of induced pluripotent stem cells from human cord blood using OCT4 and SOX2. Cell Stem Cell. 2009;5(4):353-357.

5. Germanguz I, Sedan O, Zeevi-Levin N, et al. Molecular characterization and functional properties of cardiomyocytes derived from human inducible pluripotent stem cells. J Cell Mol Med. 2011;15(1):38-51.

6. Brown ME, Rondon E, Rajesh D, et al. Derivation of induced pluripotent stem cells from human peripheral blood T lymphocytes. PLoS One. 2010;5(6):e11373.

7. Martinez-Fernandez A, Nelson TJ, Yamada S, et al. iPS programmed without c-MYC yield proficient cardiogenesis for functional heart chimerism. Circ Res. 2009;105(7):648-656.

8. Zhang J, Wilson GF, Soerens AG, et al. Functional cardiomyocytes derived from human induced pluripotent stem cells. Circ Res. 2009;104(4):e30-e41.

9. Gai H, Leung EL, Costantino PD, et al. Generation and characterization of functional cardiomyocytes using induced pluripotent stem cells derived from human fibroblasts. Cell Biol Int. 2009;33(11):1184-1193.

10. Gupta MK, Illich DJ, Gaarz A, et al. Global transcriptional profiles of beating clusters derived from human induced pluripotent stem cells and embryonic stem cells are highly similar. BMC Dev Biol. 2010;10:98

11. Fujiwara M, Yan P, Otsuji TG, et al. Induction and enhancement of cardiac cell differentiation from mouse and human induced pluripotent stem cells with cyclosporin-A. PLoS One. 2011;6(2):e16734.

12. Lin B, Kim J, Li Y, et al. High-purity enrichment of functional cardiovascular cells from human iPS cells. Cardiovasc Res. 2012; 95(3):327-335.

13. Moretti A, Bellin M, Jung CB, et al. Mouse and human induced pluripotent stem cells as a source for multipotent Is11+ cardiovascular progenitors. FASEB J. 2010;24(3):700-711.

14. Carpenter L, Carr C, Yang CT, Stuckey DJ, Clarke K, Watt SM. Efficient differentiation of human induced pluripotent stem cells generates cardiac cells that provide protection following myocardial infarction in the rat. Stem Cells Dev. 2012;21(6):977-986.

15. Kawamura M, Miyagawa S, Miki K, et al. Feasibility, safety, and therapeutic efficacy of human induced pluripotent stem cell-derived cardiomyocyte sheets in a porcine ischemic cardiomyopathy model. Circulation. 2012;126(11 Suppl 1):S29-S37.

16. Kawamura M, Miyagawa S, Fukushima S, Miki K. Development of vascular-rich tissue containing cardiomyocytes derived from human iPS Cells in vivo. Circulation. 2012;126:A11866.

17. Ye L, Xiong Q, Zhang P, Lepley M, Swingen C. Transplantation of human induced pluripotent stem cells derived cardiac cells for cardiac repair. Circulation. 2012;126:A16457.

18. Montserrat N, Bahima EG, Batlle L, et al. Generation of pig iPS cells: a model for cell therapy. J Cardiovasc Transl Res. 2011;4(2):121-130.

19. Gu M, Nguyen P, Hu S, et al. Microfluidic single cell analysis shows porcine induced pluripotent stem-cell derived endothelial cells improve myocardial function by paracrine activation. Circulation. 2012;126:A15112. 
20. Cao H, Yang P, Pu Y, et al. Characterization of bovine induced pluripotent stem cells by lentiviral transduction of reprogramming factor fusion proteins. Int J Biol Sci. 2012;8(4):498-511.

21. Lee AS, Xu D, Plews JR, et al. Preclinical derivation and imaging of autologously transplanted canine induced pluripotent stem cells. J Biol Chem. 2011;286(37):32697-32704.

22. Gore A, Li Z, Fung HL, et al. Somatic coding mutations in human induced pluripotent stem cells. Nature. 2011;471(7336):63-67.

23. Ji J, Ng SH, Sharma V, et al. Elevated coding mutation rate during the reprogramming of human somatic cells into induced pluripotent stem cells. Stem Cells. 2012;30(3):435-440.

24. Zhao T, Zhang ZN, Rong Z, Xu Y. Immunogenicity of induced pluripotent stem cells. Nature. 2011;474(7350):212-215.

25. Okita K, Nagata N, Yamanaka S. Immunogenicity of induced pluripotent stem cells. Circ Res. 2011;109(7):720-721.

26. Ohi Y, Qin H, Hong C, et al. Incomplete DNA methylation underlies a transcriptional memory of somatic cells in human iPS cells. Nat Cell Biol. 2011;13(5):541-549.

27. Rizzi R, Di Pasquale E, Portararo P, et al. Post-natal cardiomyocytes can generate iPS cells with an enhanced capacity toward cardiomyogenic re-differentation. Cell Death Differ. 2012;19(7):1162-1174.

28. Bearzi C, Rota M, Hosoda T, et al. Human cardiac stem cells. Proc Natl Acad Sci U S A. 2007;104(35):14068-14073.

29. He JQ, Vu DM, Hunt G, Chugh A, Bhatnagar A, Bolli R. Human cardiac stem cells isolated from atrial appendages stably express c-kit. PloS One. 2011;6(11):e27719.

30. Hosoda T, D'Amario D, Cabral-Da-Silva MC, et al. Clonality of mouse and human cardiomyogenesis in vivo. Proc Natl Acad Sci U S A 2009;106(40):17169-17174.

31. Goichberg P, Bai Y, D'Amario D, et al. The ephrin A1-EphA2 system promotes cardiac stem cell migration after infarction. Circ Res. 2011;108(9):1071-1083.

32. Bearzi C, Leri A, Lo Monaco F, et al. Identification of a coronary vascular progenitor cell in the human heart. Proc Natl Acad Sci USA 2009;106(37):15885-15890.

33. D'Amario D, Cabral-Da-Silva MC, Zheng H, et al. Insulin-like growth factor-1 receptor identifies a pool of human cardiac stem cells with superior therapeutic potential for myocardial regeneration. Circ Res 2011;108(12):1467-1481.

34. Kajstura J, Bai Y, Cappetta D, et al. Tracking chromatid segregation to identify human cardiac stem cells that regenerate extensively the infarcted myocardium. Circ Res. 2012;111(7):894-906.

35. Arsalan M, Woitek F, Adams V, et al. Distribution of cardiac stem cells in the human heart. ISRN Cardiol. 2012;2012:483407.

36. Opolski MP, Niewada M, Witkowski A. Letter by Opolski et al regarding article, "Patient characteristics and cell source determine the number of isolated human cardiac progenitor cells". Circulation. 2010;122(6):e422; author reply e423.

37. Itzhaki-Alfia A, Leor J, Raanani E, et al. Patient characteristics and cell source determine the number of isolated human cardiac progenitor cells. Circulation. 2009;120(25):2559-2566

38. Castaldo C, Di Meglio F, Nurzynska D, et al. CD117-positive cells in adult human heart are localized in the subepicardium, and their activation is associated with laminin-1 and alpha6 integrin expression. Stem Cells. 2008;26(7):1723-1731.

39. Chan HH, Meher Homji Z, Gomes RS, et al. Human cardiospherederived cells from patients with chronic ischaemic heart disease can be routinely expanded from atrial but not epicardial ventricular biopsies. J Cardiovasc Transl Res. 2012;5(5):678-687.

40. Gambini E, Pesce M, Persico L, et al. Patient profile modulates cardiac c-kit(+) progenitor cell availability and amplification potential. Transl Res. 2012;160(5):363-373.

41. Kubo H, Jaleel N, Kumarapeli A, et al. Increased cardiac myocyte progenitors in failing human hearts. Circulation. 2008;118(6):649-657.

42. Mishra R, Vijayan K, Colletti EJ, et al. Characterization and functionality of cardiac progenitor cells in congenital heart patients. Circulation. 2011;123(4):364-373.
43. Aghila Rani KG, Jayakumar K, Sarma PS, Kartha CC. Clinical determinants of ckit-positive cardiac cell yield in coronary disease. Asian Cardiovasc Thorac Ann. 2009;17(2):139-142.

44. Cesselli D, Beltrami AP, D'Aurizio F, et al. Effects of age and heart failure on human cardiac stem cell function. Am J Pathol. 2011; 179(1):349-366

45. Khan M, Mohsin S, Nguyen J, Alkatib M, Truffa S, Gude N. Human cardiac progenitor cells engineered with $\beta$ ARK-ct have increased survival and proliferation. Circulation. 2012;126:A13507.

46. Mohsin S, Khan M, Toko H, et al. Human cardiac progenitor cells engineered with pim-I kinase enhance myocardial repair. J Am Coll Cardiol. 2012;60(14):1278-1287.

47. Cai CL, Liang X, Shi Y, et al. Isl1 identifies a cardiac progenitor population that proliferates prior to differentiation and contributes a majority of cells to the heart. Dev Cell. 2003;5(6):877-889.

48. Bu L, Jiang X, Martin-Puig S, et al. Human ISL1 heart progenitors generate diverse multipotent cardiovascular cell lineages. Nature. 2009;460(7251):113-117.

49. Simpson DL, Mishra R, Sharma S, Goh SK, Deshmukh S, Kaushal S. A strong regenerative ability of cardiac stem cells derived from neonatal hearts. Circulation. 2012;126(11 Suppl 1):S46-S53.

50. Serradifalco C, Catanese P, Rizzuto L, et al. Embryonic and foetal Islet-1 positive cells in human hearts are also positive to c-Kit. Eur $J$ Histochem. 2011;55(4):e41.

51. White AJ, Smith RR, Matsushita S, et al. Intrinsic cardiac origin of human cardiosphere-derived cells. Eur Heart J. 2013;34(1):68-75.

52. Smith RR, Barile L, Cho HC, et al. Regenerative potential of cardiosphere-derived cells expanded from percutaneous endomyocardial biopsy specimens. Circulation. 2007;115(7):896-908.

53. Davis DR, ZhangY, Smith RR, et al. Validation of the cardiosphere method to culture cardiac progenitor cells from myocardial tissue. PLoS One. 2009;4(9):e7195.

54. Chimenti I, Smith RR, Li TS, et al. Relative roles of direct regeneration versus paracrine effects of human cardiosphere-derived cells transplanted into infarcted mice. Circ Res. 2010;106(5):971-980.

55. Machida M, Takagaki Y, Matsuoka R, Kawaguchi N. Proteomic comparison of spherical aggregates and adherent cells of cardiac stem cells. Int J Cardiol. 2011;153(3):296-305.

56. Ye J, Boyle AJ, Shih H, et al. CD45-positive cells are not an essential component in cardiosphere formation. Cell Tissue Res. 2013;351(1): 201-205.

57. Li TS, Cheng K, Malliaras K, et al. Direct comparison of different stem cell types and subpopulations reveals superior paracrine potency and myocardial repair efficacy with cardiosphere-derived cells. J Am Coll Cardiol. 2012;59(10):942-953.

58. Aghila Rani KG, Kartha CC. Effects of epidermal growth factor on proliferation and migration of cardiosphere-derived cells expanded from adult human heart. Growth Factors. 2010;28(3):157-165.

59. Cheng K, Blusztajn A, Shen D, et al. Functional performance of human cardiosphere-derived cells delivered in an in situ polymerizable hyaluronan-gelatin hydrogel. Biomaterials. 2012;33(21):5317-5324.

60. Zakharova L, Mastroeni D, Mutlu N, et al. Transplantation of cardiac progenitor cell sheet onto infarcted heart promotes cardiogenesis and improves function. Cardiovasc Res. 2010;87(1):40-49.

61. Malliaras K, Li TS, Luthringer D, et al. Safety and efficacy of allogeneic cell therapy in infarcted rats transplanted with mismatched cardiospherederived cells. Circulation. 2012;125(1):100-112.

62. Gálvez BG, Covarello D, Tolorenzi R, et al. Human cardiac mesoangioblasts isolated from hypertrophic cardiomyopathies are greatly reduced in proliferation and differentiation potency. Cardiovasc Res. 2009;83(4):707-716.

63. Emmert MY, Emmert LS, Martens A, et al. Higher frequencies of $\mathrm{BCRP}+$ cardiac resident cells in ischaemic human myocardium. Eur Heart J. Epub June 26, 2012.

64. Koninckx R, Daniels A, Windmolders S, et al. Mesenchymal stem cells or cardiac progenitors for cardiac repair? A comparative study. Cell Mol Life Sci. 2011;68(12):2141-2156. 
65. Cheng K, Shen D, Sun B, Malliaras K. Irrelevance of the c-kit-positive subpopulation to the therapeutic benefit of human cardiosphere-derived cells. Circulation. 2012;126:A13259.

66. Dixon JA, Spinale FG. Large animal models of heart failure: a critical link in the translation of basic science to clinical practice. Circ Heart Fail. 2009;2(3):262-271.

67. Bartosh TJ, Wang Z, Rosales AA, Dimitrijevich SD, Roque RS. 3D-model of adult cardiac stem cells promotes cardiac differentiation and resistance to oxidative stress. J Cell Biochem. 2008;105(2):612-623.

68. Linke A, Muller P, Nurzynska D, et al. Stem cells in the dog heart are self-renewing, clonogenic, and multipotent and regenerate infarcted myocardium, improving cardiac function. Proc Natl Acad Sci U S A. 2005;102(25):8966-8971.

69. Hou X, Appleby N, Fuentes T, et al. Isolation, characterization, and spatial distribution of cardiac progenitor cells in the sheep heart. J Clin Exp Cardiolog. 2012;8:1-6.

70. Johnston PV, Sasano T, Mills K, et al. Engraftment, differentiation, and functional benefits of autologous cardiosphere-derived cells in porcine ischemic cardiomyopathy. Circulation . 2009;120(12):1075-1083, 7 pp following 1083 .

71. Lee ST, White AJ, Matsushita S, et al. Intramyocardial injection of autologous cardiospheres or cardiosphere-derived cells preserves function and minimizes adverse ventricular remodeling in pigs with heart failure post-myocardial infarction. J Am Coll Cardiol. 2011;57(4):455-465.

72. Makkar RR, Smith RR, Cheng K, et al. Intracoronary cardiospherederived cells for heart regeneration after myocardial infarction (CADUCEUS): a prospective, randomised phase 1 trial. Lancet. 2012;379(9819):895-904.

73. Takehara N, Tsutsumi Y, Tateishi K, et al. Controlled delivery of basic fibroblast growth factor promotes human cardiosphere-derived cell engraftment to enhance cardiac repair for chronic myocardial infarction. J Am Coll Cardiol. 2008;52(23):1858-1865.
74. Terrovitis JV, Smith RR, Marban E. Assessment and optimization of cell engraftment after transplantation into the heart. Circ Res. 2010;106(3):479-494.

75. Kearns-Jonker M, Dai W, Gunthart M, et al. Genetically engineered mesenchymal stem cells influence gene expression in donor cardiomyocytes and the recipient heart. J Stem Cell Res Ther. 2012:S1.

76. Malliaras K, Cheng K, Smith R, Medendizabal A. Intracoronary cardiosphere-derived cells for heart regeneration after myocardial infarction: determinants of regenerative efficacy in the final 1-year results of the CADUCEUS trial. Circulation. 2012;126:A14781.

77. Bolli R. Effect of cardiac stem cells in patients with ischemic cardiomyopathy: interim results of the SCIPIO trial up to 2 years after therapy. Paper presented at the American Heart Association Scientific Sessions; November 4-6, 2012; Los Angeles, CA, USA.

78. Takehara N. The ALCADIA (Autologous Human Cardiac-Derived Stem Cell to Treat Ischemic Cardiomyopathy) trial. Paper presented at the American Heart Association Scientific Sessions; November 4-6, 2012; Los Angeles, CA, USA.

79. Okayama University. Transcoronary Infusion of Cardiac Progenitor Cells in Patients with Single Ventrical Physiology (TICAP). 2013. In: ClinicalTrials.gov. Available from: http://clinicaltrials.gov/ct2/show/ NCT01273857. Accessed November 14, 2012.

80. Capricor. Allogeneic Heart Stem Cells to Achieve Myocardial Reneration (ALLSTAR). 2012. In: ClinicalTrials.gov. Available from: http://clinicaltrials.gov/show/NCT01458405. Accessed November 14, 2012 .
Stem Cells and Cloning: Advances and Applications

\section{Publish your work in this journal}

Stem Cells and Cloning: Advances and Applications is an international, peer-reviewed, open access journal. Areas of interest in stem cell research include: Embryonic stem cells; Adult stem cells; Blastocysts; Cordblood stem cells; Stem cell transformation and culture; Therapeutic cloning; Umbilical cord blood and bone marrow cells; Laboratory,

\section{Dovepress}

animal and human therapeutic studies; Philosophical and ethical issues related to stem cell research. This journal is indexed on CAS. The manuscript management system is completely online and includes a quick and fair peer-review system. Visit http://www.dovepress.com/ testimonials.php to read real quotes from published authors. 